\title{
Nazolabial kist: Olgu sunumu
}

\author{
Nasolabial cyst: a case report \\ Adem Çakmak, Onuralp Kurt, Murat Salihoğlu, Atila Güngör \\ GATA Haydarpaşa Eğitim Hastanesi Kulak Burun Boğaz Kliniği, İstanbul, Türkiye
}

\begin{abstract}
Nazolabial kistler, maksillofasiyal bölgenin nadir rastlanan nonodontojenik kistlerindendir. Altta yatan patogenezinde embriyolojik doku kalıntıları suçlanmaktadır. Bu yazıda, 27 yaşında kadın hastada rastlanan nazolabial kist olgusu literatür verileri eşliğinde sunuldu.

Anahtar Sözcükler: Eksizyon; maksillofasiyal bölge; nazolabial kist.
\end{abstract}

Nazolabial kistler ilk kez 1882 yılında Zuckerkandl tarafından tanımlanmıştır. ${ }^{[1]}$ Mukoid kist, maksiller kist, nazovestibüler kist, wind kist, subalar kist, nazoglobüler kist olarak da adlandırılan bu kist için thoma nazoalveoler kist adlandırmasını önermiştir. ${ }^{[2]} \mathrm{Rao}^{[3]} 1951$ yılında nazolabial kist adlandırması önermiş ve bu kistin nazal vestibül ve üst dudak arasındaki yumuşak dokulardan geliştiğini maksilla erozyonu yaparsa nazoalveoler kist adını alması gerektiğini belirtmişlerdir. 1953 yılında ayrıntılı olarak tanımladığ 1 bu kiste araştırmacının adına atfen Klestad kisti denmiştir. ${ }^{[1]}$

Nazolabial kistler daha çok kadınlarda görülmektedir. Sol tarafta daha sıktırlar ve \%10 oranında iki taraflı olabilirler. ${ }^{[2]}$ İkinci ve beşinci dekatta daha sık görülürler. Hastalar çoğunlukla nazolabial sulkusta şişlik ile kliniğe başvurur, kistler enfekte olabilir. Nazal obstrüksiyon, üst dudağın elevasyon belirtileri görülebilir. ${ }^{[4]}$ Hastalar sıklikla burun ve üst dudak arasında birkaç yıldır bulunan kitle yakınması ile başvururlar. ${ }^{[2]}$ Fizik muayenede nazolabial olukta ele gelen hareketli düzgün yüzeyli kistik kitle palpe edilir. ${ }^{[4]}$

Görüntüleme yöntemi olarak bilgisayarlı tomografide (BT) yumuşak doku yoğunluğunda kistik yapıda yumuşak doku yerleşimli kitle görüntüsü görülür. Manyetik
Nasolabial cysts are one of those nonodonthogenic, rarely encountered maxillofacial region cysts. Embryologic tissue remnants are the culprits for the underlying pathogenesis. In this article, we report a case of nasolabial cyst in 27-year-old female in the light of literature data.

Key Words: Excision; maxillofacial region; nasolabial cyst.

rezonans görüntüleme (MRG) incelemesinde $T_{1}$ ve $T_{2}$ ağırlıklı sekanslarda hiperintens düzgün sınırlı yumuşak doku yoğunluğu izlenir. ${ }^{[5]}$

Ayırıcı tanıda odontojenik lezyonlardan foliküler, periodontal, ve rezidüel kistler ve neoplaziler bulunmaktadir. $^{[2]}$

\section{OLGU SUNUMU}

Yirmi yedi yaşında kadın hasta burun sol alt tarafında üst dudağa uzanan şişlik nedeniyle polikliniğimize başvurdu. Hastanın şişliği iki sene önce fark ettiği ve bu süreden beri şişliğin boyutunda önemli bir büyüme olmadığı öğrenildi. Hastanın bu bölgeye yönelik cerrahi ve travma öyküsü bulunmuyordu. Aile öyküsü yoktu. Hasta guatr nedeniyle medikal tedavi aliyordu. Otuz adet/gün sigara kullanıordu. Yapılan muayenesinde sol nazolabial oluğa oturan $2 \times 2 \mathrm{~cm}$ 'lik yuvarlak düzgün sınırlı, yumuşak kıvamlı sol nazal vestibülü alt konkanın alt önünden daraltan hareketli kitle lezyonu görüldü. Enflamasyon ve enfeksiyon bulgusuna rastlanmadi (Şekil 1). Oral panoramik grafide kistin nonodontojenik olduğu maksilla ve komşu kemik yapı ile ilişkili olmadığ 1 ögrrenildi. Hastanın maksillofasiyal BT incelemesinde 


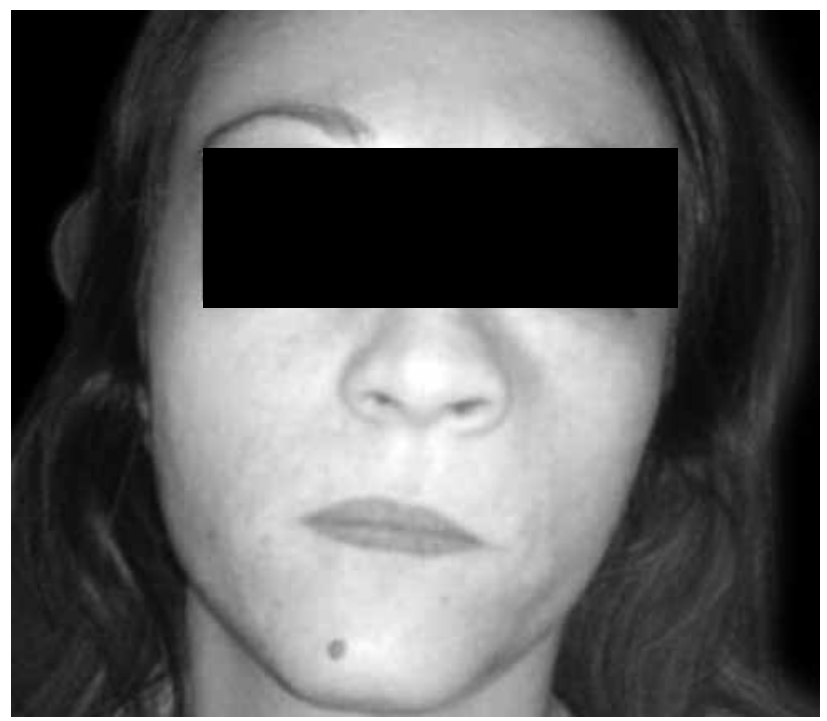

Şekil 1. Sol nazolabial bölgede $2 \times 2 \mathrm{~cm}$ çapında kitle.

nazal vestibül yayından sol alta doğru uzanan çevre kemik dokuda destrüksiyon yapmayan düzgün sinırlı kitle olduğu görüldü (Şekil 2). Cerrahi tedaviye karar verildi. Sublabial eksizyon ameliyatı uyguland. Ameliyat esnasında sol gingivobukkal insizyon yapıldı. Yumuşak dokular künt diseksiyonla geçildi. Kist patlatılmadan çevre yumuşak dokulardan diseke edildi. Gri mavi renkli $2 \times 2$ cm'lik kitle çıkarıldı. Herhangi bir tampon uygulanmadı. Hasta ameliyat günü akşamı analjezik tedavi düzenlenerek taburcu edildi. Kistin patolojik incelemesi solunum epiteli ile döşeli benign kistik kitle olarak bildirildi. Ameliyat sonrasi 1. haftada hasta zaman zaman ağzına ameliyat bölgesinden kanlı akıntı geldiğini belirtti. Muayenesinde enfeksiyon bulgusuna rastlanmad 1 ve takip önerildi. Hastanın ameliyat sonrası 1. ayında yap1lan kontrolünde kozmetik deformitenin kaybolduğu kanlı akıntı yakınmasının kalmadığı yakınmalarının tümüyle geçtiği öğrenildi (Şekil 3).

\section{TARTIŞMA}

Nazolabial kistler 2. ve 5. dekatlarda daha sık görülmekte bu kistlerin kadın cinsiyet ve sol taraf baskınlığ 1 bulunmaktadır. ${ }^{[4]}$ Bizim olgumuzda tüm bu epidemiyolojik özellikleri göstermekteydi. Bull ve ark. ${ }^{[6]}$ nazolabial bölgede şişlik oluşturan kistik kitlenin nazolabial kist için tipik bulgu olduğunu bildirmişlerdir. Bizim olgumuzun başvuru yakınması fasiyal deformite idi. Hastaların lezyonun 2-5 yıl arasında geliştiğini bildirdikleri fakat yavaş büyümesi nedeni ile tıbbi destek almadıkları El-Hamd ${ }^{[7]}$ çalışmasında belirtilmiştir. Hastamızın sol nazolabial bölgesinde son iki yıldır şişlik olması literatür ile uyumludur.

Kistin oluşum şekli hakkında iki teori ortaya atılmıştır. Birinci teori, 2. brankial arkın burun tabanı ve ala nasiyi oluştururken füzyon hattındaki aberan değişikliklerin fissür kistlerine yol açtığ 1 şelindedir. ${ }^{[2]} \mathrm{Klestad}^{[8]}$ 1953'te bu kistlerin embriyolojik fasiyal yarik epitel artıklarından köken aldıkları ve bu yüzden fissür kistleri olarak adlandırılabileceklerini belirtmişlerdir. İkinci teori ise bu kistlerin orijininin nazolakrimal duktus alt ucuna ait kalıntılar olduğu şeklindedir. Kist çeperindeki psödostratifiye kolumnar epitel nazolakrimal kanal epiteline benzemektedir. ${ }^{[2]}$ Allard $^{[9]} 10$ y1llık süre içerisinde oral kavitenin 8000 kistik lezyonunu inceledikleri bir çalışmada sadece yedi nazolabial kist olgusu ile karş1laşmışlardır. Bu sayı muhtemelen enfekte olmadan veya fasiyal deformite oluşturmadan farkedilmediğinden daha düşük çıkmaktadır. ${ }^{[5]}$

Tedavide sklerozan madde enjeksiyonu, sublabial marsupializasyon, transnazal marsupializasyon, aspirasyon, endoskopik debrider yardımlı transnazal eksizyon kullanılmıştır. ${ }^{[10]}$ Sublabial eksizyon bu hastalarda temel tedavi yöntemini oluşturmaktadır. ${ }^{[5]}$ Lee ve ark.nın ${ }^{[10]}$ 17 hastalık çalışmalarında tüm hastalarda bu yaklaşım uygulanmıştır. Nükse rastlanmamıştır.
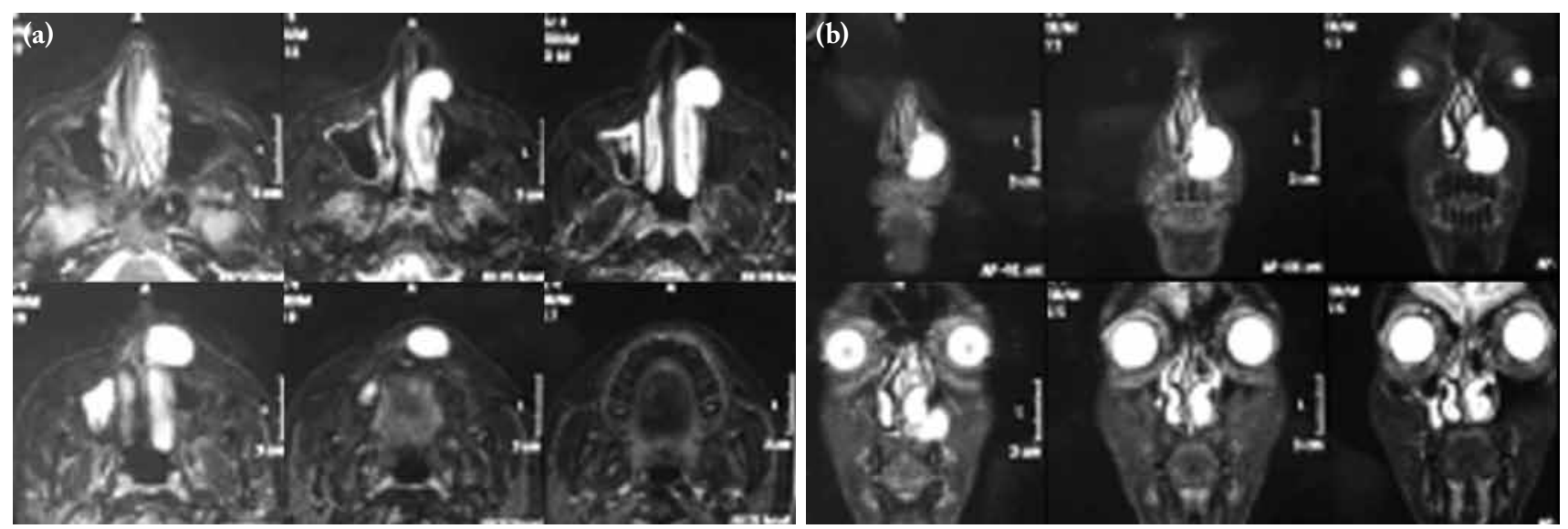

Şekil 2. Nazolabial kistin (a) aksiyal, (b) koronal bilgisayarlı tomografi görünümleri. 


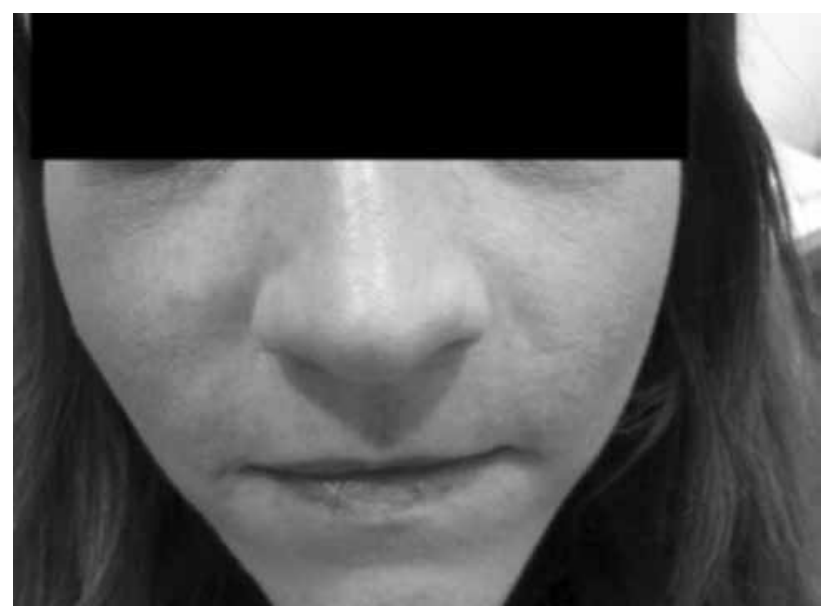

Şekil 3. Hastanın ameliyattan bir ay sonraki görünümü.

Nazolabial kistlerde anatomik olarak ağız ve burun bölgesine yakınlığı nedeniyle enfekte olma riski yüksektir. Kuriloff ${ }^{[11]}$ çalışmasında hastalarının yarısında enfeksiyon geliştiğini bildirmiştir. Başlangıç semptomu olarak kistin enfeksiyonu ve buna bağlı yakınmalar hastaların \%30'unda görülmektedir. ${ }^{[5]}$ Hastamızda tanı, tedavi ve takip aşamalarında herhangi bir enfeksiyon bulgusu saptanmadi.

Nazolabial kist tanısı her ne kadar klinik olarak konulabilen bir tan1 ise de kistin nadir olarak görülmesi genellikle hastalarda görüntüleme yöntemlerinin kullanılmasıyla sonuçlanmaktadır. ${ }^{[2]}$ Ayırıcı tanı aşamasında diş hekimi konsültasyonu istendi ve hastaya panoramik oral grafi çekildi. Nonodontojenik kist ayırımı bu şekilde yapıldı. Hastanın çekilen paranazal sinüs grafisinde maksilla önünde apertura piriformis sol taraf lateralinde $2 \times 2 \mathrm{~cm}$ 'lik kistik kitle görünümü izlendi. Kemik erozyonu yapmamıştı. Nazolabial kistler için apertura piriformis önüne yerleşim tipiktir. ${ }^{[5]}$

Hastalığın tedavisinde deformitenin düzeltilmesi nazal obstrüksiyonun giderilmesi ve enfeksiyon varsa tedavisi amaçlanmaktadır. Olgumuzda fasiyal deformite ve nazal obstrüksiyon bulunuyordu. Bu lezyon için literatürde geçen klasik cerrahi tedavi şekli sublabial yaklaşımla kistin çıkarılmasıdır. ${ }^{[5]}$ Lee ve ark. ${ }^{[10]}$ yaptıkları 20 hastalık çalışmalarında transnazal marsupializasyon ve sublabial yaklaşım yöntemlerini karşılaştırmışlardır. Transnazal marsupializasyon yaklaşımının daha kısa ameliyat zamanı düşük komplikasyon oranı kısa süren komplikasyon süresi olduğunu, bir yıllık takiplerde nüks gözlenmediğini bildirmişlerdir. Bizim hastamıza uyguladığımız sublabial yaklaşımla kist eksizyonu işleminde insizyonu takiben kist patlatılmadan yumuşak doku planında diseke edilerek çıkarıldı. Bu işlemde oluşan potansiyel boşluğun hematom veya seroma ile dolmaması için gerekli tedbirler alınmalıdır. Bizim olgumuzda baskılı pansuman yapılamamış olması ameliyat sonrası 1. haftada hastanın ağzına ara sıra kanlı akıntı gelmesine neden oldu.

Hastalığın ayırıcı tanısında bu lezyon gibi uzun sürede büyüyen, yumuşak, benign görünümlü, ağrısız olabilen neoplastik, gelişimsel, odontojenik lezyonlar akla gelmelidir. Nazoplatin duktus kisti veya insisiv kanal kisti sıklıkla karıştırılabilir. Granülasyon, kist, apse gibi periapikal enflamatuvar lezyonlar kemiği erode edip bu lezyonla karışabilir. Agresiv seyreden gelişimsel lezyonlardan keratokist aynı şekilde kemik erozyonu ile karşımıza çıkabilir. Nonodontojenik epidermoid veya epidermal inklüzyon kistleri benzer klinik tabloda olabilir. ${ }^{[5]}$ Akla gelmesi gereken diğer hastalıklar burun tabanı fronkülü, fasiyal selülit, akut maksiller sinüzit olmalıdır. ${ }^{[1]}$

Sonuç olarak, nazolabial kist kulak burun boğaz hekimlerinin karşılaşabileceği nadir maksillofasiyal kistlerdendir. Tanısı klinik olarak konulabilmesine karşın ayırıcı tanıda ek görüntüleme yöntemlerine gereksinim duyulmaktadır. Yapılacak cerrahi sonrasında baskılı pansuman yapılması olası komplikasyonları engellemede etkilidir. Bu yazıda nazolabial kist tanılı bir hastayı literatür eşliğinde sunarak bu olguların tanı tedavi ve takibi konusunda bilgilerimizi paylaştık.

\section{Çıkar çakışması beyanı}

Yazarlar bu yazının hazırlanması ve yayınlanması aşamasında herhangi bir çıkar çakışması olmadığını beyan etmişlerdir.

\section{Finansman}

Yazarlar bu yazının araştırma ve yazarlık sürecinde herhangi bir finansal destek almadıklarını beyan etmişlerdir.

\section{KAYNAKLAR}

1. Kamal R, Dahiya P, Palaskar S. Klestadt's cyst. J Nat Sci Biol Med 2011;2:128-30. doi: 10.4103/09769668.82304.

2. Aquilino RN, Bazzo VJ, Faria RJ, Eid NL, Bóscolo FN. Nasolabial cyst: presentation of a clinical case with CT and MR images. Braz J Otorhinolaryngol 2008;74:467-71.

3. Rao RV. Nasolabial cyst. J laryngol Otol 1995;69:352-4.

4. Sahin C. Nasolabial cyst. Case Rep Med 2009;2009:586201. doi: 10.1155/2009/586201.

5. Yuen HW, Julian CY, Samuel CL. Nasolabial cysts: clinical features, diagnosis, and treatment. Br J Oral Maxillofac Surg 2007;45:293-7.

6. Bull TR, McNeill KA, Milner G, Murray SM. Nasoalveolar cysts.J Laryngol Otol 1967;81:37-44.

7. El-Hamd KEAA. Nasolabial Cysts: a report of eight cases and a review of the literature. J Laryngol Otol 1999;113:747-9. 
8. Klestadt W. Nasal cysts and the facial cleft cyst theory. Annals Otol Rhinol Laryngol 1953;62:84.

9. Allard RHB. Nasolabial cyst. Review of the literrature and report of 7 cases. Int J Oral Surg 1982;11:351-9.

10. Lee JY, Baek BJ, Byun JY, Chang HS, Lee BD, Kim DW. Comparison of Conventional Excision via a Sublabial
Approach and Transnasal Marsupialization for the Treatment of Nasolabial Cysts: A Prospective Randomized Study. Clin Exp Otorhinolaryngol 2009;2:85-9. doi: 10.3342/ceo.2009.2.2.85.

11. Kuriloff DB. The nasolabial cyst-nasal hamartoma. Otolaryngol Head Neck Surg 1987;96:268-72 